\title{
First report of Helminthosporium spiciferum (Bainer) Nicot on mint (Mentha arvensis)
}

\author{
Deepak Kumar • Vikas Gupta • Vidya Sagar Verma
}

Received: 9 February 2012 / Accepted: 12 April 2013 /Published online: 11 September 2013

(C) Australasian Plant Pathology Society Inc. 2013

\begin{abstract}
Leaf blight of mint (Mentha arvensis) is a new disease caused by Helminthosporium spiciferum on mentha leaves in India. Blight symptoms were observed on mentha leaves in the month of April, 2011. The fungal pathogen causing the disease was isolated on oatmeal agar medium and the pathogenicity was confirmed on leaves of mentha plant and Koch Postulates were established. This is the first report of the occurrence of leaf blight of mentha in India.
\end{abstract}

Keywords Mentha arvensis $\cdot$ Helminthosporium spiciferum · Leaf blight

Mint, also known as mentha (Mentha arvensis), is an evergreen flowering plant belonging to family Lamiaceae. Species of mentha have a sub-cosmopolitan distribution across Europe, Africa, Asia, Australia and North America as an aromatic, perennial, rarely annual herb. Mint is grown throughout India as an evergreen perennial herb and the simple, oblong to lanceolate leaves of mint plant, arranged in opposite pairs with serrated margins are used as flavouring agent in culinary items.

Foliage of potted mint plant was observed to turn light brown at margins in the month of March, 2011. As the disease advanced, colour of the diseased portion became

D. Kumar $(\triangle) \cdot$ V. Gupta $\cdot$ V. S. Verma

Division of Plant Pathology, Sher-e-Kashmir University of

Agricultural Sciences and Technology of Jammu, Chatha,

Jammu, Jammu and Kashmir, India

e-mail: drvsverma@gmail.com dark brown. Symptoms of the disease advanced from tip or margins towards the leaf lamina. With advancement of the disease, the whole leaf turned brown, but remained flaccid. Severely affected leaves curled upwards and gave blighted look. The diseased leaves were plucked, brought to the laboratory, washed first with fresh tap water and then with sterilized water. Pieces of leaf tissue from diseased regions were dipped in mercuric chloride $(0.1 \%)$ for thirty seconds, followed by washings in three changes in autoclaved distilled water, dried on a sterilized filter paper and transferred to $90 \mathrm{~mm}$ Petri plates containing sterilized oatmeal agar medium for isolation of the causal pathogen. Light coloured, fluffy fungal colonies were grown within 5-6 days, which later turned dark. Pure cultures of the fungus were grown on oatmeal agar medium by tip culture method. Morphology of the fungus was studied. The mycelium of the fungus was filamentous, dark and septate; conidiophores short, brown, erect, bearing multi-cellular conidia, ceased to elongate with the formation of terminal conidium; conidia large phragmospores, typically obclavate, dark in colour, multicellular, 6-9 celled having transverse septa, borne singly with broader end attached to conidiophore. On the basis of the cultural and morphological characters, the fungus was identified as Helminthosporium. However, for identification of the fungus at species level, the pure cultures were sent to Indian Type Culture Collection (ITCC), a repository of the Division of Plant Pathology, Indian Agricultural Research Institute, New Delhi, India and the fungus was identified as Helminthosporium spiciferum (ID No. 8452.11).

For testing the pathogenicity of the fungus, six healthy mint (Mentha arvensis) plants were planted in pot mixture 


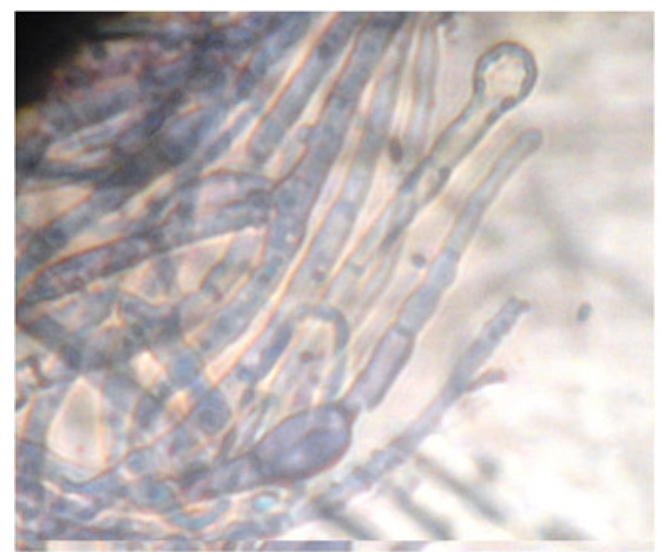

Fig. 1 Septate H. spiciferum mycelium with short conidiophore

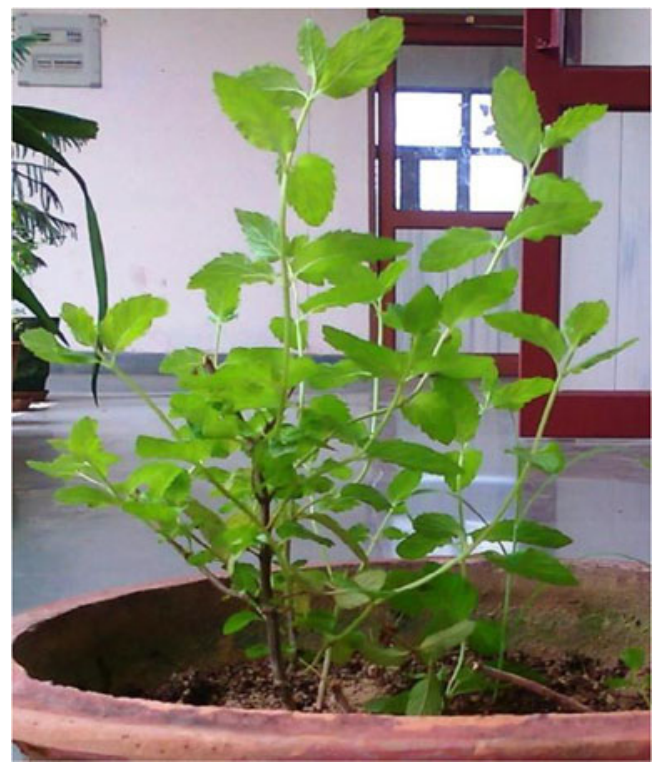

Fig. 2 Healthy mentha plant with disease-free leaves

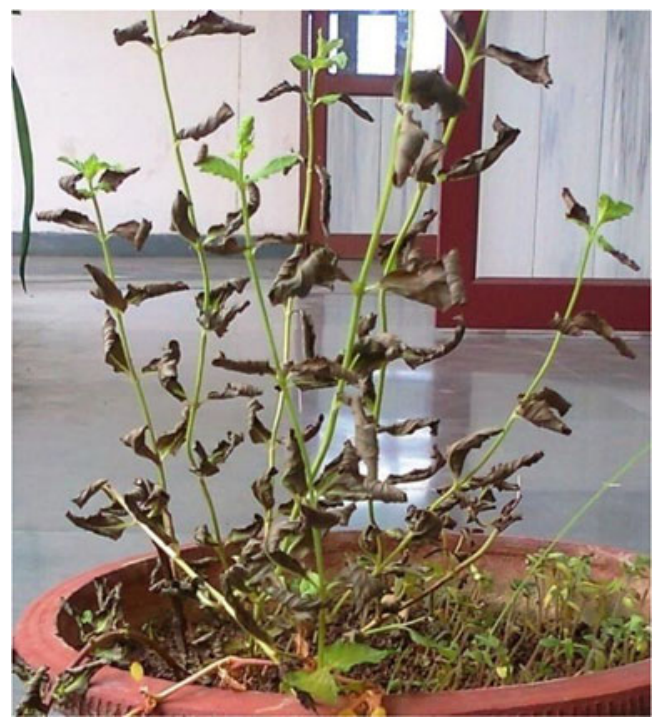

Fig. 3 Mentha plant showing leaf blight symptoms

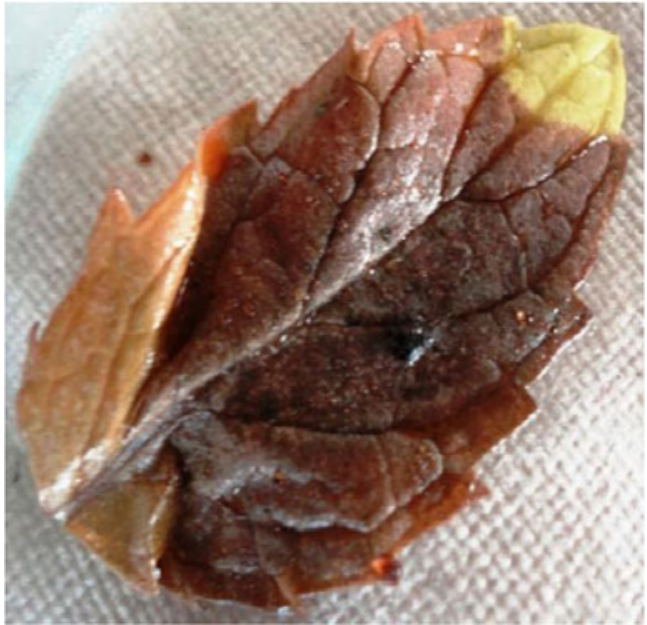

Fig. 4 Mentha leaf showing blight symptoms

containing loam soil, sand and peat moss $(1: 1: 1 \mathrm{v} / \mathrm{v})$ and allowed to establish. The leaves of five mint plants were inoculated by spraying with a conidial suspension of $10^{6}$ conidia/ml of $H$. spiciferum, while one plant was left uninoculated for comparison. All the plants were frequently sprayed with sterilized water to maintain sufficient moisture required for development of the disease. Similar blight symptoms, as observed under natural infection, developed on leaves within 10-15 days. Hence, Helminthosporium spiciferum (Bainer) Nicot (Syn Chochliobolus spicifer R.R. Nelson) was confirmed to be pathogenic causing leaf blight of mint (Nelson, 1964).

H. spiciferum has been reported to usually cause blight or leaf spot diseases of cereals and other broad leaf crops by many workers throughout the world. Ennaffah et al. (1999) reported this pathogen causing foliar lesions on rice plants in Morocco, while Pandey (2010) observed H. spiciferum causing leaf spot of eggplant in India. However, association of the fungus with mint plant causing leaf blight disease has not earlier been reported from any part of the world and this is the first global report of $H$. spiciferum (Bainer) Nicot causing leaf blight of mentha leaves from India. Figs. 1, 2, 3 and 4 .

\section{References}

Ennaffah B, Ouazzani TA, Douira A (1999) Pathogenic capacity of Helminthosporium spiciferum: Foliar parasite of rice in Morocco. J Phytopathol 14:377-379

Pandey A (2010) Studies on fungal diseases of eggplant in relation to statistical analysis and making of a disease calendar. Recent Research in Science \& Technology 2:1-3

Nelson RR (1964) Chochliobolus spicifer Nelson Mycologia 56:198 